\title{
The role of chemokines in hypertension and consequent target organ damage
}

\author{
Nathan P. Rudemiller, Steven D. Crowley* \\ Division of Nephrology Department of Medicine, Durham VA and Duke University Medical Centers, DUMC Box 103015, Durham, 27710, NC, USA
}

\section{A R T I C L E I N F O}

\section{Article history:}

Received 8 November 2016

Received in revised form 25 January 2017

Accepted 6 February 2017

Available online 6 March 2017

\section{Keywords:}

Chemokines

Hypertension

Inflammation

\begin{abstract}
A B S T R A C T
Immune cells infiltrate the kidney, vasculature, and central nervous system during hypertension, consequently amplifying tissue damage and/or blood pressure elevation. Mononuclear cell motility depends partly on chemokines, which are small cytokines that guide cells through an increasing concentration gradient via ligation of their receptors. Tissue expression of several chemokines is elevated in clinical and experimental hypertension. Likewise, immune cells have enhanced chemokine receptor expression during hypertension, driving immune cell infiltration and inappropriate inflammation in cardiovascular control centers. T lymphocytes and monocytes/macrophages are pivotal mediators of hypertensive inflammation, and these cells migrate in response to several chemokines. As powerful drivers of diapedesis, the chemokines CCL2 and CCL5 have long been implicated in hypertension, but experimental data highlight divergent, context-specific effects of these chemokines on blood pressure and tissue injury. Several other chemokines, particularly those of the CXC family, contribute to blood pressure elevation and target organ damage. Given the significant interplay and chemotactic redundancy among chemokines during disease, future work must not only describe the actions of individual chemokines in hypertension, but also characterize how manipulating a single chemokine modulates the expression and/or function of other chemokines and their cognate receptors. This information will facilitate the design of precise chemotactic immunotherapies to limit cardiovascular and renal morbidity in hypertensive patients.
\end{abstract}

(c) 2017 Elsevier Ltd. All rights reserved.

\section{Contents}

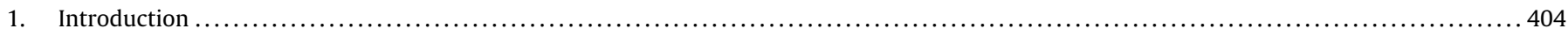

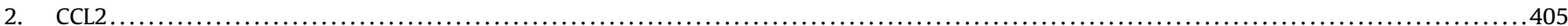

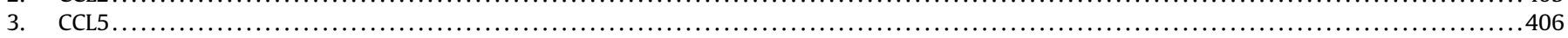

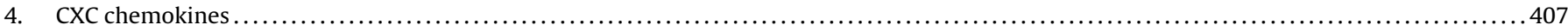

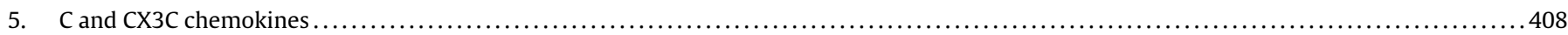

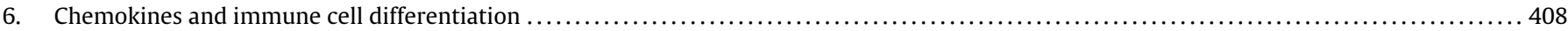

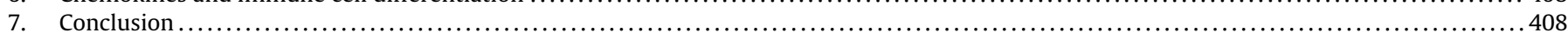

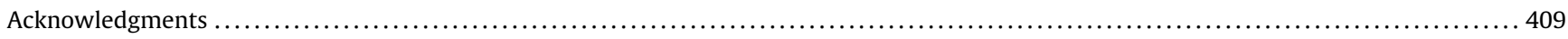

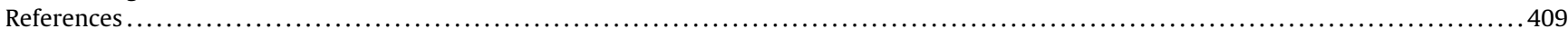

\section{Introduction}

Accumulating evidence from pre-clinical experimental models indicates that misdirected immune responses contribute to the pathogenesis of hypertension. Inflammatory cells accumulate in cardiovascular control centers such as the kidney, vasculature, and

\footnotetext{
* Corresponding author. Tel.:+1 9196849788.

E-mail address: Steven.d.crowley@duke.edu (S.D. Crowley).
}

brain where they precipitate tissue injury, hinder vascular relaxation, and promote sodium reabsorption. In human patients with hypertension, mononuclear cells similarly infiltrate the kidney and vasculature $[1,2]$. Accordingly, blocking lymphocyte proliferation or inhibiting the actions of a cytokine produced by lymphocytes and macrophages ameliorates clinical hypertension [3,4]. Thus, in experimental and human hypertension, cells of the innate and adaptive immune systems appear to drive blood pressure elevation via their recruitment into cardiovascular control tissues. Therefore, preventing the accumulation of these immune cells in cardiovascular control centers should inhibit local inflammatory injury and 
attenuate the hypertensive response. Indeed, genetic manipulations or pharmacological agents that abrogate the recruitment of immune cells, particularly monocytes/macrophages and T lymphocytes, into the vascular wall and kidney during hypertension reduce blood pressure and mitigate organ damage [5-8]. However, global interruption of immune cell trafficking could lead to complications of immunosuppression including infection and even impaired tumor surveillance. The challenge is therefore to precisely manipulate the complex system that regulates immune cell migration to treat hypertension and its attendant cardiovascular consequences while preserving key immune defense mechanisms.

Immune cells patrol the circulatory system and peripheral tissues in search of invading pathogens. However, the profile of immune cell lineages varies dramatically between organs in health and disease. Specific migration of particular immune cell subpopulations is precisely governed by their expression of adhesion molecules that bind to receptors on the vascular endothelium and by tissue-specific gradients of chemotactic signals [9]. Increased expression of specific chemokines within injured tissues directs the diapedesis of mononuclear cells across the vascular endothelium into the tissue parenchyma. Immune cells that harbor the cognate $G$ protein-coupled chemokine receptors thereby follow the increasing concentration of chemokines to the tissue source. Approximately 50 chemokine ligands and 20 chemokine receptors have been characterized and are divided into four subgroups based on the spacing of conserved cysteine residues: CC, CXC, C, and CX3C [10]. These abbreviations are followed by an "L" or "R" and a number to designate the ligand or receptor, respectively. The majority of chemokines comprise the CC and CXC families, while only two C (XCL1 and XCL2) and one CX3C (CX3CL1) chemokines have been described. The expression pattern of chemokine ligands and receptors is determined by the tissue type and physiologic context (steady state vs. disease). For example, in steady state, lymphocytes home to peripheral lymphoid organs with high specificity. CCR7 on lymphocytes interacts with its chemokine ligands, CCL21 and CCL19, which are expressed on the high endothelial venules of lymph nodes to selectively promote the entry of lymphocytes from the circulation $[11,12]$. In the context of hypertension, the chemokines that drive the infiltration of immune cells, particularly $\mathrm{T}$ lymphocytes and monocytes/macrophages, into the vasculature, kidney, and central nervous system (CNS) require further investigation. Although over 40 chemokine ligands have been described, two chemokines in particular, CCL2 and CCL5, have received the most scrutiny regarding their role in hypertension and target organ damage over the past two decades. More recently, studies have revealed important roles for CXC chemokines in this setting, while the function of $\mathrm{C}$ and $\mathrm{CX} 3 \mathrm{C}$ chemokines in hypertension will require additional investigation. Pertinent studies of chemokines in hypertension, discussed herein, are summarized in Table 1.

\section{CCL2}

CCL2 (MCP-1) guides neutrophils, monocytes, and T cells to sites of inflammation via chemokine receptor ligation [13-15]. Many cell types can secrete CCL2, including endothelial cells [16], vascular smooth muscle cells [17], renal tubular cells [18], and several cell lineages of the central nervous system-astrocytes, microglia, and neurons [19-21]. Hypertensive detriments such as inflammation [22], mechanical stress on vessels [23], oxidative stress [24], and elevated angiotensin (Ang) II levels [25,26] all elicit local CCL2 production. Consequently, T cells and monocytes, which harbor the primary CCL2 receptor, CCR2, infiltrate the tissue and exacerbate local inflammation, tissue injury, and hemodynamic dysfunction in hypertension.
Circulating levels of CCL2 are upregulated in patients with hypertension and correlate with the degree of hypertensionassociated organ damage in humans [27]. Furthermore, CCR2 protein expression on circulating monocytes is enhanced in hypertensive patients [28], leading to an enhanced sensitivity to CCL2 chemotaxis. In experimental models, the CCL2/CCR2 axis consistently exacerbates hypertensive tissue injury and inflammation. However, the effects on blood pressure of disrupting CCL2 signaling have varied with the experimental design. Pharmacological blockade of CCR2 slows the progression of, but does not ultimately reduce, established hypertension induced by a combination of angiotensin II infusion and high salt diet in rats [29]. In mice, established hypertension caused by mineralocorticoid receptor activation in combination with salt loading is partially reversed by the administration of a CCR2 inhibitor [30]. By contrast, CCL2 inhibition exacerbates renovascular hypertension, a model in which reduced perfusion to the clipped kidney drives renin secretion [31].

Unlike the use of pharmacological inhibitors, genetic deletion of CCR2 does not influence Ang II-dependent blood pressure elevation in mice $[32,33]$. These disparate results could be driven by a number of factors, including pharmacological, off-target effects that may drive phenotypic change not attributable to the intended action of the drug. Apart from technical issues, several chemokines are redundant in that they attract similar immune cell subpopulations through different receptors. CCR2 antagonists therefore may provide transient relief from immune-mediated elevations in blood pressure before compensation (i.e. the upregulation of redundant chemokines) occurs. This phenomenon of chemokine compensation has been described in allograft rejection [34], and our group has shown this to be the case in the progression of kidney fibrosis [35]. On the other hand, mice harboring genetic deletion may have already offset the absence of CCR2 throughout development. As a result, CCR2-deficient mice may have enhanced expression of redundant chemokine ligands and/or receptors that compensate for the loss of CCR2 upon induction of experimental hypertension. Temporal measurements of several chemokine ligand/receptor axes in each model would reveal if this type of compensation occurs. Furthermore, it is conceivable that the reduced renal perfusion to the clipped kidney in renovascular hypertension model may have altered the renal trafficking of injurious and reparative macrophage populations leading to a disparate effect of CCL2 in this case.

CCL2 is upregulated in the hypertensive aorta and kidney $[28,36]$, whereas CCR2 expression is enhanced on circulating monocytes during hypertension [28]. In the Ang II hypertension model, deficiency of CCR2 on bone marrow-derived cells alone attenuates macrophage infiltration and remodeling in the aorta $[28,33]$. In DOCA-salt hypertension, CCR2 inhibition reduces vascular accumulation of macrophages and lowers blood pressure [30]. Thus, in multiple experimental models, CCL2/CCR2 signaling directs vascular accumulation of monocytes/macrophages with consequent local injury. In the hypertensive kidney, CCR2 similarly drives macrophage infiltration, local oxidative stress, glomerular injury, and ultimately loss of glomerular filtration rate during reninangiotensin system (RAS) activation [29,32]. Accordingly, CCL2 inhibition attenuates macrophage infiltration and fibrosis in the Goldblatt hypertensive kidney [31]. Collectively, these studies illustrate that local macrophage accumulation via the CCL2/CCR2 axis is a principal mediator of vascular remodeling and kidney injury in hypertension. In the circulation, high surface expression of CCR2 is predominantly found on pro-inflammatory Ly6C hi monocytes [37]. Therefore, CCR2 expression on the circulating monocyte largely favors tissue accumulation of pro-inflammatory rather than reparative macrophages in this setting.

The efficacy of RAS inhibition in large numbers of hypertensive patients suggests that the RAS is inappropriately activated 
Table 1

Summary of studies investigating the role of chemokines in hypertension.

\begin{tabular}{|c|c|c|c|c|c|}
\hline Chemokine ligand or receptor & Method of inhibition & Hypertensive model & $\begin{array}{l}\text { Effect on blood } \\
\text { pressure }\end{array}$ & $\begin{array}{l}\text { Effect on organ } \\
\text { injury/dysfunction }\end{array}$ & Reference \\
\hline \multirow[t]{6}{*}{ CCR2 } & Pharm-RS102895 & Ang II + high salt in rats & Transient $\downarrow$ & $\begin{array}{l}\downarrow \text { Albuminuria and kidney } \\
\text { fibrosis }\end{array}$ & [29] \\
\hline & Pharm-INCB3344 & DOCA-salt in mice & $\downarrow$ & Not measured & [30] \\
\hline & Pharm-RS102895 & $\begin{array}{l}2 \text { kidney one clip in } \\
\text { mice }\end{array}$ & $\uparrow$ & $\begin{array}{l}\downarrow \text { Fibrosis and atrophy in } \\
\text { Goldblatt kidney }\end{array}$ & [31] \\
\hline & Genetic deletion & Ang II in mice & Not measured & $\downarrow$ Vascular remodeling & [28] \\
\hline & Genetic deletion & Ang II in mice & No effect & $\begin{array}{l}\downarrow \text { Albuminuria and kidney } \\
\text { damage; preserved GFR }\end{array}$ & [32] \\
\hline & Genetic deletion & Ang II in mice & No effect & $\downarrow$ Vascular remodeling & [33] \\
\hline \multirow[t]{2}{*}{ CCL5 } & Genetic deletion & Ang II in mice & No effect & $\begin{array}{l}\uparrow \text { Increased Albuminuria and } \\
\text { augmented glomerular and } \\
\text { interstitial injury }\end{array}$ & [35] \\
\hline & $\begin{array}{l}\text { Pharm-met-RANTES; genetic } \\
\text { deletion }\end{array}$ & Ang II in mice & No effect & $\downarrow$ Ex vivo vascular dysfunction & [52] \\
\hline CCR5 & Genetic deletion & $\begin{array}{l}\text { DOCA-salt + Ang II in } \\
\text { mice }\end{array}$ & No effect & $\begin{array}{l}\text { No effect on kidney or cardiac } \\
\text { injury }\end{array}$ & [53] \\
\hline CXCR2 & $\begin{array}{l}\text { Pharm-SB265610; genetic } \\
\text { deletion }\end{array}$ & $\begin{array}{l}\text { DOCA-salt in mice; Ang } \\
\text { II in mice }\end{array}$ & $\downarrow$ & $\begin{array}{l}\downarrow \text { Vascular hypertrophy and } \\
\text { fibrosis; preserved ex vivo } \\
\text { vascular function }\end{array}$ & [71] \\
\hline CXCR3 & Genetic deletion & Salt loading in mice & $\uparrow$ & $\begin{array}{l}\text { Enhanced ex vivo } \\
\text { vasoconstriction and blunted } \\
\text { vasodilation }\end{array}$ & [66] \\
\hline CXCR6 & Genetic deletion & Ang II in mice & No effect & $\downarrow$ Kidney injury and fibrosis & [70] \\
\hline CXCL16 & Genetic deletion & $\begin{array}{l}\text { DOCA-salt in mice; Ang } \\
\text { II in mice }\end{array}$ & No effect & $\downarrow$ Kidney injury and fibrosis & {$[67,68]$} \\
\hline CX3CR1 & Genetic deletion & DOCA-salt in mice & No effect & $\downarrow$ Kidney fibrosis & [77] \\
\hline
\end{tabular}

in essential hypertension. The primary effector molecule of the RAS, Ang II, directly elicits CCL2 production in vascular and renal cells and enhances expression of CCR2 on monocytes [25,26,38,39]. In turn, global blockade of the type 1 angiotensin $\left(\mathrm{AT}_{1}\right)$ receptor reduces CCR2 expression in circulating monocytes and CCL2 expression in aortic tissues during Ang II-dependent hypertension [28]. Similarly, $\mathrm{AT}_{1}$ receptor blockade in the renovascular hypertension model limits the induction of CCL2 expression and macrophage infiltration in the glomeruli and renal interstitium [36]. These studies reveal that $\mathrm{AT}_{1}$ receptor activation promotes CCL2-dependent vascular and kidney damage during hypertension. Our own experiments would suggest that $\mathrm{AT}_{1}$ receptors in the target organ mediate these injurious effects. We have reported that deleting $\mathrm{AT}_{1}$ receptors selectively in LysM-expressing macrophages enhances their polarization toward a pro-inflammatory M1 phenotype, increases their intrinsic expression of CCL2, and exaggerates tubulointerstitial damage to the kidney during RAS activation [40].

Stroke, or cerebrovascular accident, is among the most catastrophic complications of uncontrolled hypertension. While hypertension drives injury and inflammation in the brain, neuroinflammation conversely also promotes autonomic signals that elevate blood pressure and encourage peripheral inflammation [41]. The CCL2/CCR2 axis has been implicated in the translocation of inflammatory cells from the bone marrow to the CNS [42]. For example, spontaneously hypertensive rats have elevated CCL2 in the bone marrow and an even higher concentration of CCL2 in cerebral spinal fluid compared to normotensive rats. This concentration gradient promotes the movement of CCR2-expressing myeloid cells into the CNS [43]. Likewise, Sprague Dawley rats upregulate CCR2 on bone marrow cells in response to chronic Ang II infusion. Ang II is produced within the CNS, but circulating Ang II can also gain access to the CNS, as the blood brain barrier is often disrupted in hypertension [44]. Moreover, Ang II can directly stimulate hypothalamic neurons to upregulate CCL2 production [43], thus driving recruitment of inflammatory cells, just as seen in the kidney and vasculature.

Immune cells also directly contribute to the local production of CCL2 in hypertensive tissues, leading to further recruitment of additional inflammatory cells. For example, $\mathrm{T}$ cells isolated from the aorta and kidney, but not the spleen and blood, of Ang IIinfused mice produced more CCL2 upon T cell receptor stimulation compared to normotensive controls [45]. Moreover, infiltrating $\mathrm{T}$ cells and monocytes/macrophages produce pro-inflammatory cytokines, such as TNF- $\alpha$ and IL-1 $\beta$, that further induce CCL2 expression in resident tissue cells [46]. Thus, in a positive feedback loop mediated via CCL2 and CCR2, the influx of immune cells instigates the recruitment of even more inflammatory cells that drives hypertensive organ damage and dysfunction.

\section{CCL5}

CCL5 (RANTES), much like CCL2, is a potent chemotactic molecule for monocytes and $\mathrm{T}$ cells that is produced by several tissues that control blood pressure, including vascular endothelium and smooth muscle [47,48], glomeruli [49], renal tubules [50], and the CNS [51]. CCL5 binds multiple chemokine receptors (CCR1, -3 , and -5 ). Likewise, CCR5 binds multiple chemokine ligands (CCL3, -4 , and -5 ). However, in the context of hypertension, studies have focused on the interactions of CCL5 and its primary receptor, CCR5. Genetic deletion of CCL5 or CCR5 does not attenuate RASdependent hypertension, as CCL5-deficient and CCR5-deficient mice have similar blood pressure elevation as control mice during Ang II-induced hypertension [35,52,53]. However, unlike CCL2, which consistently exacerbates tissue injury, the influence of CCL5 signaling on hypertensive organ damage appears to be tissue- and context-dependent. Moreover, although the majority of chemokine research pertains to immune cell recruitment, chemokines harbor alternative roles that could affect blood pressure and organ injury independent of inflammation. For example, CCL5 induces migration of endothelial progenitor cells during wound healing [54]. Cataloguing non-inflammatory actions of chemokines will therefore be critical for elucidating how these molecules modulate target organ damage in hypertension.

CCL5 is upregulated in the aorta and perivascular adipose tissue (pVAT) during RAS-mediated hypertension, which coincides with an influx of myeloid cells and T cells into the pVAT, increased aor- 
tic superoxide production, and vascular dysfunction [5,52]. Genetic or pharmacological blockade of CCL5 signaling (CCL5-deficient mice and met-RANTES, respectively) blunts pVAT inflammation, reduces aortic superoxide production, and preserves vascular function without affecting blood pressure. In the CCL5-deficient mice, interferon- $\gamma$ (IFNG)-producing T cells are preferentially excluded from the pVAT infiltrate during hypertension, suggesting that CCL5 may selectively recruit IFNG-producing $\mathrm{T}$ cells to the vasculature. IFNG has been shown to drive vascular oxidative stress and dysfunction and may therefore contribute to vascular pathology in RAS-dependent hypertension [55,56].

Although CCL5 expression increases in the kidney during hypertension [53,57], its effects on renal inflammation and injury appear to be protective. Without altering blood pressure elevation in response to chronic Ang II infusion, genetic deletion of CCL5 exacerbates urinary albumin excretion, glomerular injury, and interstitial fibrosis. Moreover, CCL5-deficient mice show enhanced macrophage accumulation in the kidney, accompanied by increased expression of TNF and IL-1 $\beta$, two key drivers of RASdependent kidney injury. The protective effects of CCL5 on kidney injury have also been documented in other models of renal disease $[58,59]$. Therefore, the beneficial actions of CCL5 in hypertensive organ damage may be kidney-specific. During RAS activation, the exaggerated renal damage in the absence of CCL5 may accrue from local compensatory upregulation of CCL2. Accordingly, CCL2 blockade abrogates the enhanced renal macrophage infiltration and interstitial fibrosis in CCL5-deficient animals [35]. These studies highlight the complex interactions between chemokines with overlapping specificities. Dissecting these interactions will be paramount to the careful development of immunomodulatory therapeutics for hypertensive patients.

\section{CXC chemokines}

The CXC chemokines differ from the CC chemokines in structure, but share similar function, in that they guide the movement of cells via cognate receptor ligation. The CXC family has been implicated in immunity [10], angiogenesis [60], and cancer biology [61]. However, the role of CXC chemokines in cardiovascular disease is relatively unknown. Highlighted below are initial investigations into the effects of CXC chemokine signaling in hypertension.

The expression of chemokine receptor CXCR3 has been reported on many leukocytes, but has been shown to be especially important in the migration of activated T cells, particularly pro-inflammatory Th1 T cells that propagate injury by secreting IFNG and TNF [62]. Despite being a marker for pro-inflammatory T cells, CXCR3 may have unpredictable effects in renal disease as it also expressed on the immunosuppressive $T$ regulatory cells that specifically temper the actions of Th1 cells [63]. Three IFNG-inducible chemokine ligands bind CXCR3: CXCL9, CXCL10, and CXCL11. These chemokines are produced by a wide variety of cell types, and circulating levels of all three are elevated in hypertensive patients [64,65]. Moreover, kidney biopsies from hypertensive patients show enhanced CXCL11 expression in the tubular epithelium, coupled with robust infiltration of T lymphocytes [64]. These data would suggest that CXCR3 activity is amplified during human hypertension.

Nevertheless, in experimental models, CXCR3 ${ }^{+} \mathrm{T}$ cells limit rather than promote target organ damage accruing from hypertension. For example, CXCR3-deficient mice exhibit elevated baseline blood pressure, enhanced ex vivo vasoconstriction in response to Ang II, and blunted endothelium-dependent vasodilation compared to wild-type controls [66]. These characteristics may be related to augmented $\mathrm{AT}_{1}$ receptor expression in the vascula-

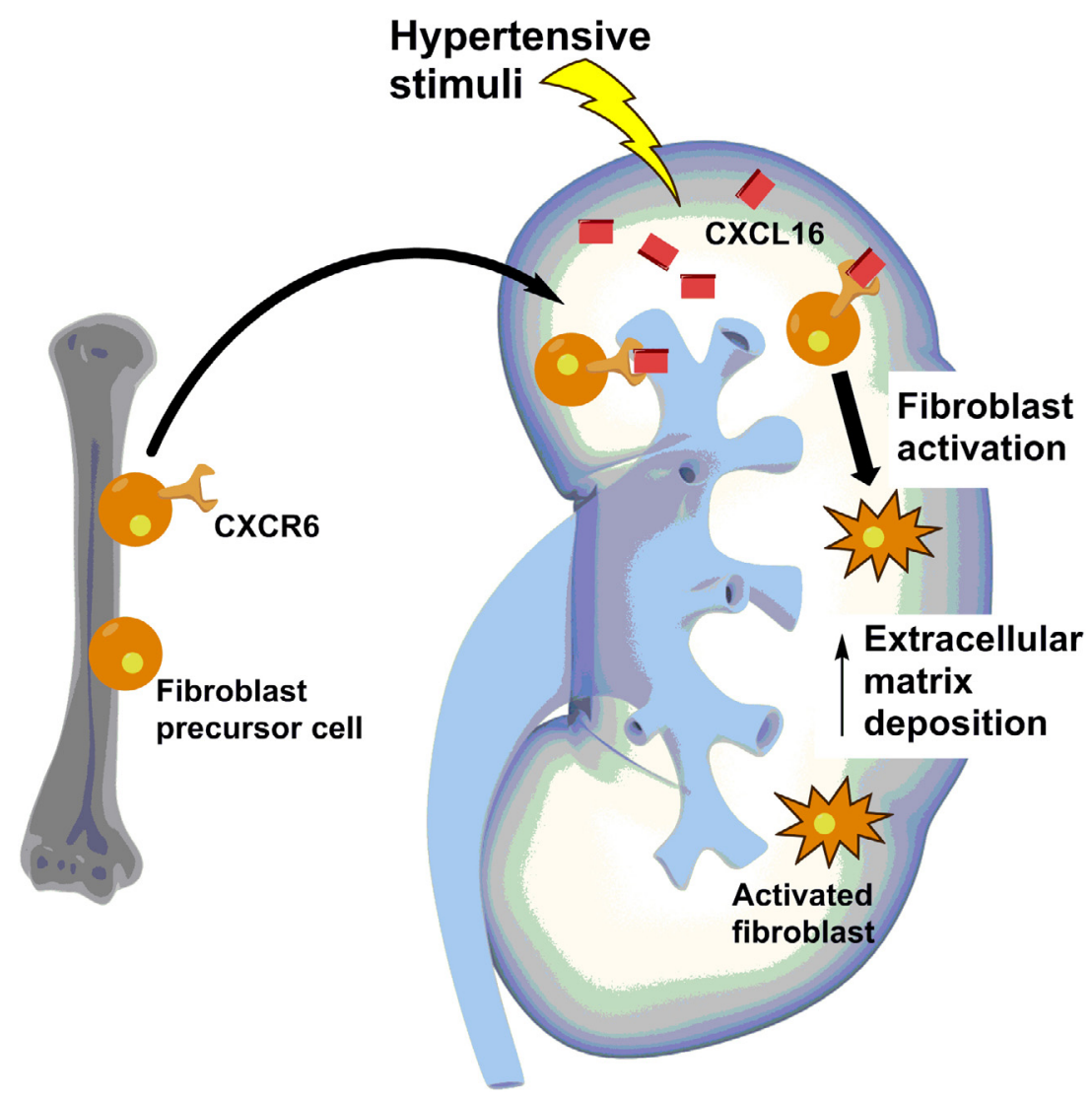

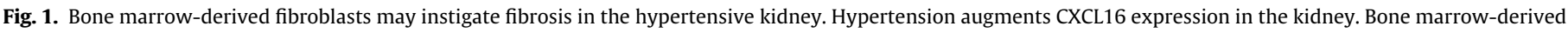

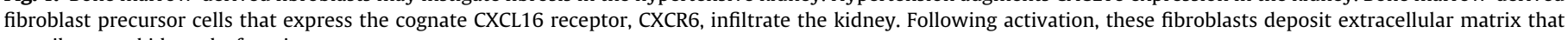
contributes to kidney dysfunction. 
ture. The mechanisms through which CXCR3 activation limits $\mathrm{AT}_{1}$ receptor expression remain unclear. Interestingly we have found with microarray analysis that $\mathrm{AT}_{1}$ receptor activation on $\mathrm{T}$ cells suppresses their expression of CXCR3 and, in turn, limits the accumulation of Th1 lymphocytes in the kidney during hypertension [57]. Thus, CXCR3 limits angiotensin receptor-mediated responses and Ang II suppresses CXCR3-dependent functions, providing another example of the complex "feedback" interactions between $\mathrm{AT}_{1}$ receptors on immune cells and the chemokine system.

CXCL16 and its cognate receptor CXCR6 propagate hypertensive kidney injury. Renal expression of CXCL16 is upregulated in Ang II-induced and DOCA-salt hypertension [67,68]. In both hypertensive models, CXCL16-deficient mice have similar blood pressure to wild-type controls. However, the CXCL16-deficient kidneys are protected from $\mathrm{T}$ cell and macrophage infiltration, inflammation, injury, and fibrosis. CXCL16 was previously shown to enhance the recruitment of bone marrow-derived fibroblasts to the injured kidney in a model of renal fibrosis [69]. In hypertension, CXCL16-deficient mice have similarly blunted accumulation of bone marrow-derived fibroblasts in the kidney, a plausible mechanism for the reduced renal fibrosis seen in these animals. The same group observed analogous results in the CXCR6-deficient mouse during chronic Ang II infusion [70], supporting the notion that CXCR6 signaling facilitates scar formation in the hypertensive kidney by driving recruitment of bone marrow-derived fibroblasts (Fig. 1).

CXCR2 regulates neutrophil and myeloid cell motility through the binding of several CXC ligands, including CXCL1 through CXCL8. CXCR2-expressing leukocytes accumulate in the aorta during experimental hypertension, which coincides with vascular inflammation, dysfunction, and injury. Wang et al. recently employed genetic deletion and pharmacological blockade of CXCR2 to show that CXCR2 inhibition significantly attenuates Ang II-induced and DOCA-salt hypertension and associated vascular inflammation and injury [71]. Bone marrow transplant studies using CXCR2-deficient mice confirmed that the deleterious effects of CXCR2 expression in hypertension were mediated by its actions on immune cells. Thus, CXCR2 signaling augments blood pressure elevation and consequent vascular injury in hypertension. Further studies will be required to understand whether CXCR2 secondarily raises blood pressure by instigating vascular injury or the converse.

\section{5. $C$ and $C X 3 C$ chemokines}

Limited data describe the chemotactic role of XCL1 and XCL2, and no studies to our knowledge have yet explored the role of the $C$ chemokines in hypertension. However, XCL1 directs the movement of CD8+ dendritic cells [72], and dendritic cells play an important role in instigating blood pressure elevation [73]. The function of XCL2 is largely unknown.

CX3CL1 (Fractalkine) exists in two forms: a membraneanchored leukocyte adhesion molecule mainly expressed on endothelial cells or a soluble factor that attracts $\mathrm{T}$ cells and monocytes via the CX3CR1 receptor [74-76]. In mice, DOCA-salt hypertension significantly increases CX3CL1 mRNA expression in whole kidney, and the protein localizes to tubular epithelial and vascular endothelial cells on immunohistochemistry [77]. CX3CR1deficient animals have a preserved hypertensive response, but are partially protected from renal fibrosis in this model. In these studies, CX3CL1 recruited F4/80-expressing myeloid cells into the kidney during hypertension. A similar pro-inflammatory effect of CX3CL1 was documented in the pathogenesis of pulmonary hypertension [78].

\section{Chemokines and immune cell differentiation}

The myeloid and lymphoid compartments display remarkable phenotypic heterogeneity. Generally, M1 macrophages promote inflammation while M2 macrophages are reparative and antiinflammatory. Th1 and Th17 T cells are thought to drive several immune-mediated pathologies, while $\mathrm{T}$ regulatory cells suppress inflammation. Thus, in hypertension, the extent of inflammatory tissue injury is largely attributed to the composition of local immune cell populations. Indeed, augmenting inflammatory or anti-inflammatory populations in vivo exacerbates or diminishes hypertensive pathology, respectively [79-82].

Beyond the canonical function of chemotaxis, chemokines influence immune cell differentiation. For example, in Leishmanial braziliensis infection, many monocytes that infiltrate the parasitic lesion differentiate into pro-inflammatory dendritic cells that are essential to resolve infection. The absence of CCR2 does not affect the recruitment of monocytes to lesions [83]. However, CCR2deficient monocytes showed blunted monocyte-to-dendritic cell conversion, leading to unresolved infection. Furthermore, T cell differentiation is heavily influenced by chemokines [84]. For instance, CXCR3 not only guides $\mathrm{T}$ cells to sites of inflammation, but also affects $\mathrm{CD}^{+} \mathrm{T}$ cell differentiation $[85,86]$. Following antigen experience, $\mathrm{CD}^{+} \mathrm{T}$ cells lacking CXCR3 preferentially differentiate into memory cells, not short-lived effector cells, thus amplifying the memory pool. $\mathrm{CD}^{+}$memory $\mathrm{T}$ cells have been implicated in hypertension [87], and augmented memory $\mathrm{T}$ cell pools may explain why CXCR3-deficient mice experience exacerbated hypertensive pathology [66]. Recent work also highlights the ability of T cells to trans-differentiate between subsets at sites of inflammation [88]. Accordingly, chemokines may encourage hypertensive pathology not only by driving the infiltration of immune cells, but also by promoting differentiation of pro-inflammatory immune subsets in cardiovascular organs. This paradigm requires further investigation in the setting of hypertension.

\section{Conclusion}

Over 40 known chemokines have functions that are not mutually exclusive, can be promiscuous in receptor ligation, and appear to have divergent, tissue-specific functions in the setting of cardiovascular disease (Table 1). CCL5, for example, exacerbates vascular injury but protects the kidney in Ang II-induced hypertension. The exaggerated renal damage associated with CCL5-deficiency may culminate from tissue-specific compensation, whereby blockade of one chemokine upregulates expression of redundant chemokines that could actually worsen pathology. In our studies, genetic deletion of CCL5 results in the upregulation of renal CCL2 that exacerbates RAS-dependent inflammation and renal fibrosis [35]. Background strain could also contribute to disparate actions of chemokines in murine experimental hypertension. CCL5-deficient mice on the $\mathrm{C} 57 \mathrm{BL} / 6$ background are protected from vascular damage in hypertension, whereas CCL5-deficient mice on the 129SVE strain exhibit worse renal injury, suggesting that genetic background differences may impact chemokine signaling during disease. Such a finding complicates the direct application of experimental findings to the treatment of hypertension in a genetically diverse human population.

The subsets of immune cells recruited to hypertensive organs determine the inflammatory microenvironment. Although several chemokines, including CCL2, CCL5, and CX3CR1, attract both monocytes and $\mathrm{T}$ cells, the distinct subsets of monocytes and $\mathrm{T}$ cells guided by each chemokine may vary. For instance, circulating monocytes are categorized into two subsets - "patrolling/alternative" and "inflammatory" - that differentially 
express CCR2 and CX3CR1 [37]. Moreover, T cells are parsed into at least four functionally distinct subsets that express chemokine receptors in a context-dependent manner [89]. Inflammatory monocytes express abundant CCR2, are heavily recruited to sites of injury, and infiltrate the hypertensive vasculature and kidney [90]. On the other hand, patrolling monocytes express high levels of CX3CR1 and are thought to be primarily reparative. However, CX3CR1 protects $\mathrm{T}$ cells from apoptosis and drives Th1 and Th17 cytokine production, which is known to exacerbate hypertensive pathology [91]. Therefore, CCL2/CCR2 may exacerbate hypertensive pathology via the recruitment of pro-inflammatory monocytes, whereas CX3CL1/CX3CR1 can drive injury through Th1 and Th17 cytokine production.

Although myeloid and lymphoid populations drive hypertensive pathology, the exact subpopulations that mediate compartmentspecific pathology require further study. For example, we have seen that altering $T$ cell recruitment influences glomerular damage in the hypertensive kidney whereas modulating macrophage polarization and recruitment impacts tubulointerstitial injury [40,57]. Glomerulosclerosis is a relatively late finding in human hypertensive kidney disease, so it seems plausible that regulating the recruitment of proinflammatory $\mathrm{T}$ cells may be particularly helpful in patients with malignant hypertension and glomerular injury. By contrast, targeting myeloid cell recruitment to limit tubulointerstitial disease may benefit patients who are developing kidney fibrosis during hypertension. On the other hand, in acute kidney injury, macrophages exhibit shifting polarizations during different phases of disease pathogenesis [92], suggesting that immunomodulatory therapies may need to target different myeloid cell subsets at early versus later, more severe stages of hypertension. In several hypertensive models, chemokine inhibition modulated end organ damage without altering blood pressure. Clinically, chemokine therapy could supplement the standard regimen of blood pressure lowering treatments to further mitigate organ injury. Moreover, patients with resistant hypertension may benefit most from chemokine modulation. Given these uncertainties, further pre-clinical experiments coupled with descriptive clinical studies will need to pinpoint the specific inflammatory cell subsets that drive blood pressure elevation or hypertensive pathology. Subsequently, the configuration of chemokines that drive the infiltration or differentiation of these pro-hypertensive immune cells can potentially be regulated to safely attenuate end-organ damage in hypertensive patients.

\section{Acknowledgments}

NIH grants DK087893, HL128355; Veterans Health Administration, Office of Research and Development, Biomedical Laboratory Research and Development Grant BX000893; Duke O'Brien Center for Kidney Research.

\section{References}

[1] M.D. Hughson, G.C. Gobe, W.E. Hoy, R.D. Manning Jr., R. Douglas-Denton, J.F. Bertram, Associations of glomerular number and birth weight with clinicopathological features of African Americans and whites, Am. J. Kidney Dis. 52 (1) (2008) 18-28.

[2] S.C. Sommers, A.S. Relman, R.H. Smithwick, Histologic studies of kidney biopsy specimens from patients with hypertension, Am. J. Pathol. 34 (4) (1958) 685-715.

[3] J. Herrera, A. Ferrebuz, E.G. MacGregor, B. Rodriguez-Iturbe, Mycophenolate mofetil treatment improves hypertension in patients with psoriasis and rheumatoid arthritis, J. Am. Soc. Nephrol. 17 (12 Suppl 3) (2006) S218-S225.

[4] S. Yoshida, T. Takeuchi, T. Kotani, N. Yamamoto, K. Hata, K. Nagai, T. Shoda, S. Takai, S. Makino, T. Hanafusa, Infliximab, a TNF-alpha inhibitor, reduces 24-h ambulatory blood pressure in rheumatoid arthritis patients, J. Hum. Hypertens. 28 (3) (2014) 165-169.

[5] T.J. Guzik, N.E. Hoch, K.A. Brown, L.A. McCann, A. Rahman, S. Dikalov, J. Goronzy, C. Weyand, D.G. Harrison, Role of the T cell in the genesis of angiotensin II induced hypertension and vascular dysfunction, J. Exp. Med. 204 (10) (2007) 2449-2460.
[6] P. Wenzel, M. Knorr, S. Kossmann, J. Stratmann, M. Hausding, S. Schuhmacher, S.H. Karbach, M. Schwenk, N. Yogev, E. Schulz, M. Oelze, S. Grabbe, H. Jonuleit, C. Becker, A. Daiber, A. Waisman, T. Munzel, Lysozyme M-positive monocytes mediate angiotensin II-induced arterial hypertension and vascular dysfunction, Circulation 124 (12) (2011) 1370-1381.

[7] PhysGen Knockout PN. Rudemiller, H. Lund, H.J. Jacob, A.M. Geurts, D.L. Mattson, CD247 modulates blood pressure by altering T-lymphocyte infiltration in the kidney, Hypertension 63 (3) (2014) 559-564.

[8] W.G. McMaster, A. Kirabo, M.S. Madhur, D.G. Harrison, Inflammation, immunity, and hypertensive end-organ damage, Circ. Res. 116 (6) (2015) 1022-1033.

[9] O. Barreiro, P. Martin, R. Gonzalez-Amaro, F. Sanchez-Madrid, Molecular cues guiding inflammatory responses, Cardiovasc. Res. 86 (2) (2010) 174-182.

[10] J.W. Griffith, C.L. Sokol, A.D. Luster, Chemokines and chemokine receptors: positioning cells for host defense and immunity, Annu. Rev. Immunol. 32 (2014) 659-702.

[11] R. Forster, A. Schubel, D. Breitfeld, E. Kremmer, I. Renner-Muller, E. Wolf, M. Lipp, CCR7 coordinates the primary immune response by establishing functional microenvironments in secondary lymphoid organs, Cell 99 (1) (1999) 23-33.

[12] R. Forster, A.C. Davalos-Misslitz, A. Rot, CCR7 and its ligands: balancing immunity and tolerance, Nat. Rev. Immunol. 8 (5) (2008) 362-371.

[13] M.E. Fuentes, S.K. Durham, M.R. Swerdel, A.C. Lewin, D.S. Barton, J.R. Megill, R. Bravo, S.A. Lira, Controlled recruitment of monocytes and macrophages to specific organs through transgenic expression of monocyte chemoattractant protein-1, J. Immunol. 155 (12) (1995) 5769-5776.

[14] I.F. Charo, R.M. Ransohoff, The many roles of chemokines and chemokine receptors in inflammation, N. Engl. J. Med. 354 (6) (2006) 610-621.

[15] B. Johnston, A.R. Burns, M. Suematsu, T.B. Issekutz, R.C. Woodman, P. Kubes, Chronic inflammation upregulates chemokine receptors and induces neutrophil migration to monocyte chemoattractant protein-1, J. Clin. Invest. 103 (9) (1999) 1269-1276.

[16] A. Sica, J.M. Wang, F. Colotta, E. Dejana, A. Mantovani, J.J. Oppenheim, C.G. Larsen, C.O. Zachariae, K. Matsushima, Monocyte chemotactic and activating factor gene expression induced in endothelial cells by IL-1 and tumor necrosis factor, J. Immunol. 144 (8) (1990) 3034-3038.

[17] J.M. Wang, A. Sica, G. Peri, S. Walter, I.M. Padura, P. Libby, M. Ceska, I. Lindley, F. Colotta, A. Mantovani, Expression of monocyte chemotactic protein and interleukin- 8 by cytokine-activated human vascular smooth muscle cells, Arterioscler. Thromb. 11 (5) (1991) 1166-1174.

[18] W. Prodjosudjadi, J.S. Gerritsma, N. Klar-Mohamad, A.F. Gerritsen, J.A. Bruijn, M.R. Daha, L.A. van Es, Production and cytokine-mediated regulation of monocyte chemoattractant protein-1 by human proximal tubular epithelial cells, Kidney Int. 48 (5) (1995) 1477-1486.

[19] M. Hayashi, Y. Luo, J. Laning, R.M. Strieter, M.E. Dorf, Production and function of monocyte chemoattractant protein-1 and other beta-chemokines in murine glial cells, J. Neuroimmunol. 60 (1-2) (1995) 143-150.

[20] P.K. Peterson, S. Hu, J. Salak-Johnson, T.W. Molitor, C.C. Chao, Differential production of and migratory response to beta chemokines by human microglia and astrocytes, J. Infect. Dis. 175 (2) (1997) 478-481.

[21] G. Banisadr, R.D. Gosselin, P. Mechighel, P. Kitabgi, W. Rostene, S.M. Parsadaniantz, Highly regionalized neuronal expression of monocyte chemoattractant protein-1 (MCP-1/CCL2) in rat brain: evidence for its colocalization with neurotransmitters and neuropeptides, J. Comp. Neurol. 489 (3) (2005) 275-292.

[22] B.J. Rollins, Chemokines, Blood 90 (3) (1997) 909-928.

[23] Y.J. Shyy, H.J. Hsieh, S. Usami, S. Chien, Fluid shear stress induces a biphasic response of human monocyte chemotactic protein 1 gene expression in vascular endothelium, Proc. Natl. Acad. Sci. U.S.A. 91 (11) (1994) 4678-4682

[24] V. Lakshminarayanan, D.W. Beno, R.H. Costa, K.A. Roebuck, Differential regulation of interleukin- 8 and intercellular adhesion molecule- 1 by $\mathrm{H}_{2} \mathrm{O}_{2}$ and tumor necrosis factor-alpha in endothelial and epithelial cells, J. Biol. Chem. 272 (52) (1997) 32910-32918.

[25] Capers Qt, R.W. Alexander, P. Lou, H. De Leon, J.N. Wilcox, N. Ishizaka, A.B. Howard, W.R. Taylor, Monocyte chemoattractant protein-1 expression in aortic tissues of hypertensive rats, Hypertension 30 (6) (1997) 1397-1402

[26] X.L. Chen, P.E. Tummala, M.T. Olbrych, R.W. Alexander, R.M. Medford, I.I. Angiotensin, induces monocyte chemoattractant protein-1 gene expression in rat vascular smooth muscle cells, Circ. Res. 83 (9) (1998) 952-959.

[27] M. Tucci, C. Quatraro, M.A. Frassanito, F. Silvestris, Deregulated expression of monocyte chemoattractant protein-1 (MCP-1) in arterial hypertension: role in endothelial inflammation and atheromasia, J. Hypertens. 24 (7) (2006) 1307-1318.

[28] M. Ishibashi, K. Hiasa, O. Zhao, S. Inoue, K. Ohtani, S. Kitamoto, M. Tsuchihashi, T. Sugaya, I.F. Charo, S. Kura, T. Tsuzuki, T. Ishibashi, A. Takeshita, K. Egashira, Critical role of monocyte chemoattractant protein-1 receptor CCR2 on monocytes in hypertension-induced vascular inflammation and remodeling, Circ. Res. 94 (9) (2004) 1203-1210.

[29] A.A. Elmarakby, J.E. Quigley, J.J. Olearczyk, A. Sridhar, A.K. Cook, E.W. Inscho, D.M. Pollock, J.D. Imig, Chemokine receptor $2 \mathrm{~b}$ inhibition provides renal protection in angiotensin II-salt hypertension, Hypertension 50 (6) (2007) 1069-1076.

[30] C.T. Chan, J.P. Moore, K. Budzyn, E. Guida, H. Diep, A. Vinh, E.S. Jones, R.E. Widdop, J.A. Armitage, S. Sakkal, S.D. Ricardo, C.G. Sobey, G.R. Drummond, Reversal of vascular macrophage accumulation and hypertension by a CCR2 
antagonist in deoxycorticosterone/salt-treated mice, Hypertension 60 (5) (2012) 1207-1212

[31] S. Kashyap, G.M. Warner, S.P. Hartono, R. Boyilla, B.E. Knudsen, A.S. Zubair, K. Lien, K.A. Nath, S.C. Textor, L.O. Lerman, J.P. Grande, Blockade of CCR2 reduces macrophage influx and development of chronic renal damage in murine renovascular hypertension, Am. J. Physiol. Renal Physiol. 310 (5) (2016) F372-F384.

[32] T.D. Liao, X.P. Yang, Y.H. Liu, E.G. Shesely, M.A. Cavasin, W.A. Kuziel, P.J. Pagano, O.A. Carretero, Role of inflammation in the development of renal damage and dysfunction in angiotensin II-induced hypertension, Hypertension 52 (2) (2008) 256-263.

[33] E. Bush, N. Maeda, W.A. Kuziel, T.C. Dawson, J.N. Wilcox, H. DeLeon, W.R. Taylor, CC chemokine receptor 2 is required for macrophage infiltration and vascular hypertrophy in angiotensin II-induced hypertension, Hypertension 36 (3) (2000) 360-363.

[34] G.T. Schnickel, S. Bastani, G.R. Hsieh, A. Shefizadeh, R. Bhatia, M.C. Fishbein, J Belperio, A. Ardehali, Combined CXCR3/CCR5 blockade attenuates acute and chronic rejection, J. Immunol. 180 (7) (2008) 4714-4721.

[35] N.P. Rudemiller, M.B. Patel, J.D. Zhang, A.D. Jeffs, N.S. Karlovich, R. Griffiths, M.J. Kan, A.F. Buckley, M.D. Gunn, S.D. Crowley, C-C motif chemokine 5 attenuates angiotensin II-dependent kidney injury by limiting renal macrophage infiltration, Am. J. Pathol. 186 (November (11)) (2016) 2846-2856

[36] K.F. Hilgers, A. Hartner, M. Porst, M. Mai, M. Wittmann, C. Hugo, D. Ganten, H. Geiger, R. Veelken, J.F. Mann, Monocyte chemoattractant protein-1 and macrophage infiltration in hypertensive kidney injury, Kidney Int. 58 (6) (2000) 2408-2419.

[37] C. Shi, E.G. Pamer, Monocyte recruitment during infection and inflammation, Nat. Rev. Immunol. 11 (11) (2011) 762-774.

[38] M. Ruiz-Ortega, M. Ruperez, O. Lorenzo, V. Esteban, J. Blanco, S. Mezzano, J. Egido, Angiotensin II regulates the synthesis of proinflammatory cytokines and chemokines in the kidney, Kidney Int. Suppl. 82 (2002) S12-S22.

[39] T. Morita, T. Imai, T. Yamaguchi, T. Sugiyama, S. Katayama, G. Yoshino, Induction of heme oxygenase- 1 in monocytes suppresses angiotensin II-elicited chemotactic activity through inhibition of CCR2: role of bilirubin and carbon monoxide generated by the enzyme, Antioxid. Redox Signal. 5 (4) (2003) 439-447.

[40] J.D. Zhang, M.B. Patel, R. Griffiths, P.C. Dolber, P. Ruiz, M.A. Sparks, J. Stegbauer, H. Jin, J.A. Gomez, A.F. Buckley, W.S. Lefler, D. Chen, S.D. Crowley, Type 1 angiotensin receptors on macrophages ameliorate IL-1 receptor-mediated kidney fibrosis, J. Clin. Invest. 124 (5) (2014) 2198-2203.

[41] P.J. Marvar, S.R. Thabet, T.J. Guzik, H.E. Lob, L.A. McCann, C. Weyand, F.J. Gordon, D.G. Harrison, Central and peripheral mechanisms of T-lymphocyte activation and vascular inflammation produced by angiotensin II-induced hypertension, Circ. Res. 107 (2) (2010) 263-270.

[42] K. Ataka, A. Asakawa, K. Nagaishi, K. Kaimoto, A. Sawada, Y. Hayakawa, R. Tatezawa, A. Inui, M. Fujimiya, Bone marrow-derived microglia infiltrate into the paraventricular nucleus of chronic psychological stress-loaded mice, PLoS ONE 8 (11) (2013) e81744.

[43] M.M. Santisteban, N. Ahmari, J.M. Carvajal, M.B. Zingler, Y. Qi, S. Kim, J. Joseph, F. Garcia-Pereira, R.D. Johnson, V. Shenoy, M.K. Raizada, J. Zubcevic, Involvement of bone marrow cells and neuroinflammation in hypertension, Circ. Res. 117 (2) (2015) 178-191.

[44] V.C. Biancardi, S.J. Son, S. Ahmadi, J.A. Filosa, J.E. Stern, Circulating angiotensin II gains access to the hypothalamus and brain stem during hypertension via breakdown of the blood-brain barrier, Hypertension 63 (3) (2014) 572-579.

[45] Z. Wei, I. Spizzo, H. Diep, G.R. Drummond, R.E. Widdop, A. Vinh, Differential phenotypes of tissue-infiltrating T cells during angiotensin II-induced hypertension in mice, PLoS ONE 9 (12) (2014) e114895.

[46] A.W. Ho, C.K. Wong, C.W. Lam, Tumor necrosis factor-alpha up-regulates the expression of CCL2 and adhesion molecules of human proximal tubular epithelial cells through MAPK signaling pathways, Immunobiology 213 (7) (2008) 533-544.

[47] N.J. Jordan, M.L. Watson, R.J. Williams, A.G. Roach, T. Yoshimura, J. Westwick, Chemokine production by human vascular smooth muscle cells: modulation by IL-13, Br. J. Pharmacol. 122 (4) (1997) 749-757.

[48] H. Laubli, K.S. Spanaus, L. Borsig, Selectin-mediated activation of endothelial cells induces expression of CCL5 and promotes metastasis through recruitment of monocytes, Blood 114 (20) (2009) 4583-4591.

[49] G. Wolf, F.N. Ziyadeh, F. Thaiss, J. Tomaszewski, R.J. Caron, U. Wenzel, G. Zahner, U. Helmchen, R.A. Stahl, I.I. Angiotensin, Stimulates expression of the chemokine RANTES in rat glomerular endothelial cells. Role of the angiotensin type 2 receptor, J. Clin. Invest. 100 (5) (1997) 1047-1058.

[50] T. Wada, K. Furuichi, C. Segawa-Takaeda, M. Shimizu, N. Sakai, S.I. Takeda, K. Takasawa, H. Kida, K.I. Kobayashi, N. Mukaida, Y. Ohmoto, K. Matsushima, H. Yokoyama, MIP-1alpha and MCP-1 contribute to crescents and interstitial lesions in human crescentic glomerulonephritis, Kidney Int. 56 (3) (1999) 995-1003.

[51] S.S. Gouraud, H. Waki, M.E. Bhuiyan, M. Takagishi, H. Cui, A. Kohsaka, J.F. Paton, M. Maeda, Down-regulation of chemokine Ccl5 gene expression in the NTS of SHR may be pro-hypertensive, J. Hypertens. 29 (4) (2011) 732-740.

[52] T.P. Mikolajczyk, R. Nosalski, P. Szczepaniak, K. Budzyn, G. Osmenda, D. Skiba, A. Sagan, J. Wu, A. Vinh, P.J. Marvar, B. Guzik, J. Podolec, G. Drummond, H.E. Lob, D.G. Harrison, T.J. Guzik, Role of chemokine RANTES in the regulation of perivascular inflammation, T-cell accumulation, and vascular dysfunction in hypertension, FASEB J. 30 (May (5)) (2016) 1987-1999.
[53] C. Krebs, C. Fraune, R. Schmidt-Haupt, J.E. Turner, U. Panzer, M.N. Quang, A. Tannapfel, J. Velden, R.A. Stahl, U.O. Wenzel, CCR5 deficiency does not reduce hypertensive end-organ damage in mice, Am. J. Hypertens. 25 (4) (2012) 479-486.

[54] Y. Ishida, A. Kimura, Y. Kuninaka, M. Inui, K. Matsushima, N. Mukaida, T. Kondo, Pivotal role of the CCL5/CCR5 interaction for recruitment of endothelial progenitor cells in mouse wound healing, J. Clin. Invest. 122 (2) (2012) 711-721

[55] S. Kossmann, M. Schwenk, M. Hausding, S.H. Karbach, M.I. Schmidgen, M. Brandt, M. Knorr, H. Hu, S. Kroller-Schon, T. Schonfelder, S. Grabbe, M. Oelze, A. Daiber, T. Munzel, C. Becker, P. Wenzel, Angiotensin II-induced vascular dysfunction depends on interferon-gamma-driven immune cell recruitment and mutual activation of monocytes and NK-cells, Arterioscler. Thromb. Vasc. Biol. 33 (6) (2013) 1313-1319.

[56] S.A. Manea, A. Todirita, M. Raicu, A. Manea, C/EBP transcription factors regulate NADPH oxidase in human aortic smooth muscle cells, J. Cell. Mol. Med. 18 (7) (2014) 1467-1477.

[57] J.D. Zhang, M.B. Patel, Y.S. Song, R. Griffiths, J. Burchette, P. Ruiz, M.A. Sparks, M. Yan, D.N. Howell, J.A. Gomez, R.F. Spurney, T.M. Coffman, S.D. Crowley, A novel role for type 1 angiotensin receptors on $\mathrm{T}$ lymphocytes to limit target organ damage in hypertension, Circ. Res. 110 (12) (2012) 1604-1617.

[58] H.J. Anders, M. Frink, Y. Linde, B. Banas, M. Wornle, C.D. Cohen, V. Vielhauer, P.J. Nelson, H.J. Grone, D. Schlondorff, CC chemokine ligand 5/RANTES chemokine antagonists aggravate glomerulonephritis despite reduction of glomerular leukocyte infiltration, J. Immunol. 170 (11) (2003) 5658-5666.

[59] C.M. Lloyd, M.E. Dorf, A. Proudfoot, D.J. Salant, J.C. Gutierrez-Ramos, Role of MCP-1 and RANTES in inflammation and progression to fibrosis during murine crescentic nephritis, J. Leukoc. Biol. 62 (5) (1997) 676-680.

[60] J.A. Belperio, M.P. Keane, D.A. Arenberg, C.L. Addison, J.E. Ehlert, M.D. Burdick, R.M. Strieter, CXC chemokines in angiogenesis, J. Leukoc. Biol. 68 (1) (2000) $1-8$.

[61] J. Vandercappellen, J. Van Damme, S. Struyf, The role of CXC chemokines and their receptors in cancer, Cancer Lett. 267 (2) (2008) 226-244.

[62] S. Qin, J.B. Rottman, P. Myers, N. Kassam, M. Weinblatt, M. Loetscher, A.E. Koch, B. Moser, C.R. Mackay, The chemokine receptors CXCR3 and CCR5 mark subsets of T cells associated with certain inflammatory reactions, J. Clin. Invest. 101 (4) (1998) 746-754.

[63] H.J. Paust, J.H. Riedel, C.F. Krebs, J.E. Turner, S.R. Brix, S. Krohn, J. Velden, T. Wiech, A. Kaffke, A. Peters, S.B. Bennstein, S. Kapffer, C. Meyer-Schwesinger, C. Wegscheid, G. Tiegs, F. Thaiss, H.W. Mittrucker, O.M. Steinmetz, R.A. Stahl, U. Panzer, CXCR3+ regulatory T cells control TH1 responses in crescentic GN, J. Am. Soc. Nephrol. 27 (7) (2016) 1933-1942.

[64] J.C. Youn, H.T. Yu, B.J. Lim, M.J. Koh, J. Lee, D.Y. Chang, Y.S. Choi, S.H. Lee, S.M. Kang, Y. Jang, O.J. Yoo, E.C. Shin, S. Park, Immunosenescent CD8+ T cells and $\mathrm{C}-\mathrm{X}-\mathrm{C}$ chemokine receptor type 3 chemokines are increased in human hypertension, Hypertension 62 (1) (2013) 126-133.

[65] C. Stumpf, C. Auer, A. Yilmaz, P. Lewczuk, L. Klinghammer, M. Schneider, W.G. Daniel, R.E. Schmieder, C.D. Garlichs, Serum levels of the Th1 chemoattractant interferon-gamma-inducible protein (IP) 10 are elevated in patients with essential hypertension, Hypertens. Res. 34 (4) (2011) 484-488.

[66] H.H. Hsu, K. Duning, H.H. Meyer, M. Stolting, T. Weide, S. Kreusser, T. van Le, C. Gerard, R. Telgmann, S.M. Brand-Herrmann, H. Pavenstadt, M.J. Bek, Hypertension in mice lacking the CXCR3 chemokine receptor, Am. J. Physiol. Renal Physiol. 296 (4) (2009) F780-F789.

[67] H. Liang, Z. Ma, H. Peng, L. He, Z. Hu, Y. Wang, CXCL16 deficiency attenuates renal injury and fibrosis in salt-sensitive hypertension, Sci. Rep. 6 (2016) 28715.

[68] Y. Xia, M.L. Entman, Y. Wang, Critical role of CXCL16 in hypertensive kidney injury and fibrosis, Hypertension 62 (6) (2013) 1129-1137.

[69] G. Chen, S.C. Lin, J. Chen, L. He, F. Dong, J. Xu, S. Han, J. Du, M.L. Entman, Y. Wang, CXCL16 recruits bone marrow-derived fibroblast precursors in renal fibrosis, J. Am. Soc. Nephrol. 22 (10) (2011) 1876-1886.

[70] Y. Xia, X. Jin, J. Yan, M.L. Entman, Y. Wang, CXCR6 plays a critical role in angiotensin II-induced renal injury and fibrosis, Arterioscler. Thromb. Vasc. Biol. 34 (7) (2014) 1422-1428.

[71] L. Wang, X.C. Zhao, W. Cui, Y.Q. Ma, H.L. Ren, X. Zhou, J. Fassett, Y.Z. Yang, Y. Chen, Y.L. Xia, J. Du, H. Li, Genetic and pharmacologic inhibition of the chemokine receptor CXCR2 prevents experimental hypertension and vascular dysfunction, Circulation 134 (November (18)) (2016) 1353-1368.

[72] B.G. Dorner, M.B. Dorner, X. Zhou, C. Opitz, A. Mora, S. Guttler, A. Hutloff, H.W Mages, K. Ranke, M. Schaefer, R.S. Jack, V. Henn, R.A. Kroczek, Selective expression of the chemokine receptor XCR1 on cross-presenting dendritic cells determines cooperation with CD8+ T cells, Immunity 31 (5) (2009) 823-833.

[73] A. Kirabo, V. Fontana, A.P. de Faria, R. Loperena, C.L. Galindo, J. Wu, A.T. Bikineyeva, S. Dikalov, L. Xiao, W. Chen, M.A. Saleh, D.W. Trott, H.A. Itani, A. Vinh, V. Amarnath, K. Amarnath, T.J. Guzik, K.E. Bernstein, X.Z. Shen, Y. Shyr, S.C. Chen, R.L. Mernaugh, C.L. Laffer, F. Elijovich, S.S. Davies, H. Moreno, M.S. Madhur, J. Roberts 2nd, D.G. Harrison, DC isoketal-modified proteins activate $\mathrm{T}$ cells and promote hypertension, J. Clin. Invest. 124 (10) (2014) 4642-4656.

[74] J.F. Bazan, K.B. Bacon, G. Hardiman, W. Wang, K. Soo, D. Rossi, D.R. Greaves, A Zlotnik, T.J. Schall, A new class of membrane-bound chemokine with a CX3C motif, Nature 385 (6617) (1997) 640-644.

[75] P. Fraticelli, M. Sironi, G. Bianchi, D. D’Ambrosio, C. Albanesi, A. Stoppacciaro, M. Chieppa, P. Allavena, L. Ruco, G. Girolomoni, F. Sinigaglia, A. Vecchi, A. 
Mantovani, Fractalkine (CX3CL1) as an amplification circuit of polarized Th1 responses, J. Clin. Invest. 107 (9) (2001) 1173-1181.

[76] T. Imai, K. Hieshima, C. Haskell, M. Baba, M. Nagira, M. Nishimura, M. Kakizaki, S. Takagi, H. Nomiyama, T.J. Schall, O. Yoshie, Identification and molecular characterization of fractalkine receptor CX3CR1, which mediates both leukocyte migration and adhesion, Cell 91 (4) (1997) 521-530.

[77] K. Shimizu, K. Furuichi, N. Sakai, K. Kitagawa, K. Matsushima, N. Mukaida, S. Kaneko, T. Wada, Fractalkine and its receptor, CX3CR1, promote hypertensive interstitial fibrosis in the kidney, Hypertens. Res. 34 (6) (2011) 747-752.

[78] K. Balabanian, A. Foussat, P. Dorfmuller, I. Durand-Gasselin, F. Capel, L. Bouchet-Delbos, A. Portier, A. Marfaing-Koka, R. Krzysiek, A.C. Rimaniol, G. Simonneau, D. Emilie, M. Humbert, CX(3)C chemokine fractalkine in pulmonary arterial hypertension, Am. J. Respir. Crit. Care. Med. 165 (10) (2002) 1419-1425.

[79] T. Barhoumi, D.A. Kasal, M.W. Li, L. Shbat, P. Laurant, M.F. Neves, P. Paradis, E.L. Schiffrin, T regulatory lymphocytes prevent angiotensin II-induced hypertension and vascular injury, Hypertension 57 (3) (2011) 469-476.

[80] K.H. Shah, P. Shi, J.F. Giani, T. Janjulia, E.A. Bernstein, Y. Li, T. Zhao, D.G. Harrison, K.E. Bernstein, X.Z. Shen, Myeloid suppressor cells accumulate and regulate blood pressure in hypertension, Circ. Res. 117 (10) (2015) 858-869.

81] D.W. Trott, S.R. Thabet, A. Kirabo, M.A. Saleh, H. Itani, A.E. Norlander, J. Wu, A Goldstein, W.J. Arendshorst, M.S. Madhur, W. Chen, C.I. Li, Y. Shyr, D.G. Harrison, Oligoclonal CD8+ T cells play a critical role in the development of hypertension, Hypertension 64 (5) (2014) 1108-1115.

[82] D.A. Kasal, T. Barhoumi, M.W. Li, N. Yamamoto, E. Zdanovich, A. Rehman, M.F. Neves, P. Laurant, P. Paradis, E.L. Schiffrin, T regulatory lymphocytes prevent aldosterone-induced vascular injury, Hypertension 59 (2) (2012) 324-330.

83] D.L. Costa, D.S. Lima-Junior, M.S. Nascimento, L.A. Sacramento, R.P. Almeida, V. Carregaro, J.S. Silva, CCR2 signaling contributes to the differentiation of protective inflammatory dendritic cells in Leishmania braziliensis infection, J. Leukoc. Biol. 100 (2) (2016) 423-432.
[84] S.A. Luther, J.G. Cyster, Chemokines as regulators of T cell differentiation, Nat. Immunol. 2 (2) (2001) 102-107.

[85] M. Kurachi, J. Kurachi, F. Suenaga, T. Tsukui, J. Abe, S. Ueha, M. Tomura, K. Sugihara, S. Takamura, K. Kakimi, K. Matsushima, Chemokine receptor CXCR3 facilitates CD8(+) T cell differentiation into short-lived effector cells leading to memory degeneration, J. Exp. Med. 208 (8) (2011) 1605-1620.

[86] J.K. Hu, T. Kagari, J.M. Clingan, M. Matloubian, Expression of chemokine receptor CXCR3 on T cells affects the balance between effector and memory CD8 T-cell generation, Proc. Natl. Acad. Sci. U.S.A. 108 (21) (2011) E118-E127.

[87] H.A. Itani, L. Xiao, M.A. Saleh, J. Wu, M.A. Pilkinton, B.L. Dale, N.R. Barbaro, J.D. Foss, A. Kirabo, K.R. Montaniel, A.E. Norlander, W. Chen, R. Sato, L.G. Navar, S.A. Mallal, M.S. Madhur, K.E. Bernstein, D.G. Harrison, CD70 exacerbates blood pressure elevation and renal damage in response to repeated hypertensive stimuli, Circ. Res. 118 (April (8)) (2016) 1233-1243.

[88] N. Komatsu, K. Okamoto, S. Sawa, T. Nakashima, M. Oh-hora, T. Kodama, S. Tanaka, J.A. Bluestone, H. Takayanagi, Pathogenic conversion of Foxp3+ T cells into TH17 cells in autoimmune arthritis, Nat. Med. 20 (1) (2014) 62-68.

[89] S.L. Reiner, Decision making during the conception and career of CD4+ T cells, Nat. Rev. Immunol. 9 (2) (2009) 81-82.

[90] S. Kossmann, H. Hu, S. Steven, T. Schonfelder, D. Fraccarollo, Y. Mikhed, M. Brahler, M. Knorr, M. Brandt, S.H. Karbach, C. Becker, M. Oelze, J. Bauersachs, J. Widder, T. Munzel, A. Daiber, P. Wenzel, Inflammatory monocytes determine endothelial nitric-oxide synthase uncoupling and nitro-oxidative stress induced by angiotensin II, J. Biol. Chem. 289 (40) (2014) 27540-27550.

[91] L. Dong, J. Nordlohne, S. Ge, B. Hertel, A. Melk, S. Rong, H. Haller, S. von Vietinghoff, T Cell CX3CR1 mediates excess atherosclerotic inflammation in renal impairment, J. Am. Soc. Nephrol. 27 (6) (2016) 1753-1764.

[92] S. Lee, S. Huen, H. Nishio, S. Nishio, H.K. Lee, B.S. Choi, C. Ruhrberg, L.G. Cantley, Distinct macrophage phenotypes contribute to kidney injury and repair, J. Am. Soc. Nephrol. 22 (2) (2011) 317-326. 